\title{
Social Support and Neighborhood Stressors Among African American Youth: Networks and Relations to Self-Worth
}

\author{
Susan D. McMahon · Erika D. Felix • \\ Thara Nagarajan
}

Published online: 13 July 2010

(c) The Author(s) 2010. This article is published with open access at Springerlink.com

\begin{abstract}
Although neighborhood stressors have a negative impact on youth, and social support can play a protective role, it is unclear what types and sources of social support may contribute to positive outcomes among at-risk youth. We examined the influences of neighborhood disadvantage and social support on global self-worth among low-income, urban African American youth, both concurrently and longitudinally. We examined social support from both a structural and functional perspective, and tested the main-effects and the stress-buffering models of social support. Participants included $82-130$ youth, in 6th8th grade, who completed self-report measures. Network support results suggest participants received emotional, tangible, and informational support most often from mothers and other female relatives, with friends, fathers, and teachers also playing important roles. Model testing accounted for neighborhood stressors and support from various sources, revealing support from close friends was associated with concurrent self-worth; whereas, parent support predicted self-worth longitudinally, above and beyond initial levels of self-worth. The findings provide evidence for the main-effects model of social support and not the stress-buffering model. Our findings illustrate the
\end{abstract}

\footnotetext{
S. D. McMahon ( $\square)$

DePaul University, 2219 N. Kenmore Ave, Chicago,

IL 60614, USA

e-mail: smcmahon@depaul.edu

E. D. Felix

University of California, Santa Barbara, CA, USA

T. Nagarajan

DePaul University Family and Community Services,

Chicago, IL, USA
}

importance of extended family networks and the types of support that youth rely upon in African American impoverished communities, as well as how support contributes to global self-worth. Implications and suggestions for future research and intervention are discussed.

Keywords Parent support · Friend support . Chronic neighborhood stressors - Self-worth . African American youth · Main-effects model

\section{Inroduction}

There are many factors that affect a child's sense of him/ herself, including the amount and type of social support the child receives from parents, teachers, and peers. Social support may affect a child by directly increasing his/her sense of self-worth, and/or buffering the adverse effects of stressors on self-worth (Cohen and Wills 1985). A growing body of empirical work has begun to explore social support among African American youth (e.g., Brown 2008; Gaylord-Harden et al. 2007; Kerpelman et al. 2008; Paxton et al. 2004); however, few longitudinal studies have been conducted. This study addresses the roles of social support and chronic neighborhood stressors in relation to self-worth in at-risk African American youth.

Chronic stressors (e.g., economic hardship, experiences of oppression, and neighborhood violence) are often intercorrelated (e.g., Belle 1984) and lead to more significant problems when acute (i.e., temporary) stressors are present (Marin et al. 2007). Neighborhood disadvantage accounts for a comprehensive array of stressors, including crime, poverty, drug and gang activity, racism, unemployment, lack of safety, and below-standard housing (e.g., Dubow et al. 1997). Neighborhood disadvantage has been shown to 
be significantly related to competencies and behavior among adolescents (Luthar 1991).

When growing up in highly stressful communities that can erode competencies and well-being, global self-worth may be a particularly salient asset. Global self-worth is a discrete value judgment that a person makes regarding him or herself that is greater than the sum of domain-specific self-competencies (Harter et al. 1998). Theorists posit that adolescents have variability in their sense of global selfworth as their identities develop within the context of different relationships (e.g., Harter et al. 1998; Rosenberg 1986). High self-worth may protect adolescents from problems and lead to better socio-emotional adjustment (Owens 1994). Few studies have focused on self-worth among African American adolescents, and the urban poor are particularly neglected in this arena.

\section{Social Support}

Social support can serve different functional roles, including emotional/esteem, tangible/instrumental, and informational (Cohen and Wills 1985). Emotional support enables people to talk about their feelings and feel validated. Tangible or instrumental support involves providing material aid, such as money, resources, and help. Informational support can take the form of advice, knowledge about how a system works (such as how to access resources), or skills required to accomplish a goal (such as how to solve a problem with a classmate). Parents, extended family, teachers, and peers can all provide necessary support to at-risk youth. Further, non-parental women provide an important support network to children in African American communities (e.g., Hirsch et al. 2002). Yet it is not clear who provides what types of support, and many studies investigate only one source of support.

\section{Models of Social Support}

Models have been proposed to describe how social support can influence psychosocial adjustment in the context of stressors, with a particular emphasis on the main effects and stress-buffering models (Cohen and Wills 1985). The main-effects model suggests that social support has a general positive effect on psychological outcomes, even while controlling for stressors; it is tested as a direct effect. Large social support networks provide individuals with many resources, including consistent positive interactions and affect, sense of stability, and avoidance of negative situations that directly influence adjustment regardless of stress level. The stress-buffering model suggests differential effects of support, depending on the level of stressors (a moderating influence tested by an interaction effect). Youth with higher levels of stressors will benefit more from support than youth with lower levels of stressors (compared to similar benefits for everyone in the main effect model). Social support may offset the negative effects of poverty, racism, and exposure to violence (e.g., Holt and Espelage 2005; Rosenfeld et al. 2006). Both models take into account stressors and are important to assess among at-risk youth.

Social support has been linked with improved academic performance, self-confidence, and behavioral adjustment (e.g., Gaylord-Harden et al. 2007; Kerpelman et al. 2008). The amount of social support provided by various sources (parents, best friends, classmates, teachers and romantic interests) has been associated with sense of self-worth (Robinson 1995), and family support has specifically been linked with general social competence and self-worth (e.g., Cauce et al. 1996) among diverse populations. Of studies that included stressors for a test of the main-effects model, there is support for this model of social support among urban, minority adolescents (e.g., Benhorin and McMahon 2008; Hill et al. 1996; Pina et al. 2008; Zimmerman et al. 2000). Zimmerman et al. (2000) found evidence for both cross-sectional and longitudinal main effects for parental support when examining stressful life events in relation to anxiety and depression among African American adolescent males. They also examined support from friends, but did not find a cross-sectional or longitudinal relation to outcomes. Benhorin and McMahon (2008) found that friend support, but not classmate support, was associated with lower rates of teacher-reported aggressive behavior (cross-sectionally), taking into account exposure to community violence. Hill and colleagues (1996) found both family and peer support helped reduce anxiety symptoms among African Americans exposed to community violence. Thus, although social support has been linked with selfworth, most research examining the main-effects model has examined psychological problems, rather than strengthsbased outcomes, such as self-worth.

The findings supporting the stress-buffering models among youth, particularly urban adolescents, have been somewhat mixed. Some studies show evidence of moderation (Benhorin and McMahon 2008; Henrich and Shahar 2008; Holt and Espelage 2005; Ozer and Weinstein 2004; Scarpa and Haden 2006) and others do not (e.g., Paxton et al. 2004; Salazar et al. 2004; White et al. 1998). Zimmerman et al.'s (2000) test of stress-buffering found that in most cases, there was not buffering; however parental support did have a concurrent, but not a longitudinal buffering effect on the relation between stressors and mental health for African American males. The buffering effect of social support depends on the outcome, as family support moderated the relationship between community violence exposure and depressive symptoms, but not posttraumatic 
stress symptoms (Overstreet et al. 1999). Consequently, more research is needed to test these models with urban atrisk youth in relation to strengths-based outcomes.

\section{Current Study}

This study aims to better understand the relations between chronic neighborhood stressors, social support, and self-worth. First, we examine who provides different types of social support among African American youth. We expect mothers and friends to be central providers of support, and we believe that extended families and teachers will be listed as frequent providers of support. Second, we test the main-effects and stress-buffering models of social support with four sources of support (parents, teachers, close friends, and classmates) concurrently and longitudinally. We expect the main-effects model to be supported, given the stronger direct effects in the literature and mixed evidence for the buffering model. We are interested in looking at these relations crosssectionally to capture current relations, given changes that can occur with different sources of support. We anticipate that close friend and parent support are likely to be the most influential in relation to global self-worth, yet friends change across time, so the effects of their support may be less enduring across time (e.g., Chan and Poulin 2007).

\section{Method}

\section{Participants}

African American students in grades 6-8 from two Chicago Public Schools participated in this study. There were four classes in each school, and all students were invited to participate during school hours. There were 133 students in the cross-sectional sample (completed pre-test measures of interest), and 114 students who completed post-test measures, leading to a sample of 85 students in the longitudinal sample (students who completed both pre-test and posttest). The smaller sample size for completed pre-test and post-test data is largely due to high rates of absenteeism, truancy, and mobility in these schools. In the cross-sectional sample, there were 50 boys and 83 girls, and students in 6th $(N=50), 7$ th $(N=49)$ and 8 th $(N=34)$ grade. In the longitudinal sample, there were 35 boys and 50 girls, with 31 students in 6th, 37 in 7th, and 17 in 8 th grade. The student body at these schools was 98.9-100\% African American and $97.8 \%$ of the students lived in low-income households (living in families receiving public aid, or living in institutions for neglected or delinquent children, or supported in foster homes with public funds, or eligible to receive free or reduced price lunch; Chicago Public Schools 1999).

\section{Measures}

\section{Neighborhood Disadvantage}

This 11-item scale was developed to assess chronic, community level stressors such as poverty, exposure to violence, racism, and prevalence of gangs and drugs (Dubow et al. 1997). The yes/no response format yielded a total possible sum score of 11 (See Table 1 for descriptive information on all measures). Dubow et al. (1997) established validity through comparing children's reports of experiencing each neighborhood disadvantage stressor with Census data on neighborhood crime rates. In the current study, the Cronbach's Coefficient Alpha was acceptable at .73 (Time 1). Although this sample may seem homogenous in terms of neighborhood factors, given the low-income statistics, there is actually considerable variability in youth perceptions of neighborhood disadvantage, perhaps at least partially due to differences in exposure and the range of problems youth experience within a neighborhood.

\section{Social Networks}

Participants' network of social support was assessed by three questions: "Who helps you when you need to talk to somebody about your feelings?" (emotional support), "Who gives you something that you would like or need but don't have?" (instrumental/ tangible support), and "Who helps you when you need to know something you're not sure of?" (informational support) (Dubow and Ullman 1989). The child lists up to five people who provide each type of support and his/her relationship to the person. In a study of 361 third through fifth graders from two urban and two suburban lower middle class schools, Dubow and Ullman (1989) found test-retest reliabilities of .52-.54 for the number of network members for each type of support. In addition, adequate consistency was found in the top three choices of who was and was not identified as a support over a 4-week period. We examined each participant's list of supportive people at Time 1 to describe who provides emotional, instrumental, and informational support for these youth.

\section{Social Support Scale for Children}

Support and positive regard from parents, teachers, classmates, and close friends was assessed through this 24-item scale, with 4 subscales (Harter 1985a). The child is asked to decide which part of a statement is most like him/her, and then to rate the statement as being "sort of true for me" 
Table 1 Means, standard deviations, and correlations of study measures

\begin{tabular}{|c|c|c|c|c|c|c|c|}
\hline & Mean (SD) & Teacher & Classmate & Friend & $\begin{array}{l}\text { Neighborhood } \\
\text { disadvantage }\end{array}$ & Self-worth T1 & Self-worth T2 \\
\hline Parent support & $3.46(.61)$ & $.30 * *$ & $.55^{* *}$ & $.22 * *$ & -.05 & $.29 * *$ & $.28 * *$ \\
\hline Teacher support & $3.34(.53)$ & & $.21 * *$ & $.22 * *$ & .06 & .11 & .03 \\
\hline Classmate support & $3.05(.60)$ & & & $.40 * *$ & $-.16^{*}$ & $.27 * *$ & .18 \\
\hline Friend support & $3.24(.66)$ & & & & .06 & $.32 * *$ & $.24 *$ \\
\hline Neighborhood disadvantage & $6.85(2.56)$ & & & & & $-.18 *$ & -.16 \\
\hline Self-worth T1 & $3.18(.62)$ & & & & & & $.58 * *$ \\
\hline Self-worth T2 & $3.27(.66)$ & & & & & & \\
\hline
\end{tabular}

$*$ denotes significance at $p<.05 ; * *$ denotes significance at $p<.01$

or "really true for me". The scoring for each item ranged from one to four, with four indicating the most support. Correlations between subscales and other related constructs, such as social acceptance and social skills, ranged from .28 to .69 and reliability ranged from .74 to .88 (Harter 1985a). In the current study, Cronbach's Alpha Coefficients ranged from .67 to .77 at Time 1 . The means for each of these subscales were calculated and used to test the main-effects and stress-buffering models to examine the extent to which support from each of these four sources contribute to global self-worth in the context of neighborhood disadvantage.

\section{Global Self-Worth}

A 6-item subscale of the Self-Perception Profile for Children (Harter 1985b) assesses students' feelings about their self-worth, and items are scored from 1-4 with higher scores yielding higher self-worth. Harter asserts that children over the age of 8 can make a global judgment about their own self-worth, and that it is more accurate to ask students directly about their feelings of self-worth rather than to sum students' responses about their feelings of competence in various domains. Regarding validity, correlations between global self-worth and other domains of self-competence range from .30 to .73 (Harter 1985b). Reliability was assessed from four samples of lower to upper middle class youth and ranged from .78 to .84 (Harter 1985b). In the current study, Cronbach's Alpha Coefficient was .68 at both Time 1 and 2 .

\section{Procedure}

After obtaining IRB and school approval, data were collected in the fall (September) and spring (May) of one academic year. Information, with opportunities to decline permission, was distributed to parents through the students, school newsletters, and parent report card pick-up. Active student assent was obtained prior to classroom administration of surveys; surveys were read aloud to control for reading ability.

\section{Results}

Correlations suggest that neighborhood disadvantage, and support from parents, classmates, and close friends were associated with self-worth cross-sectionally (See Table 1). Parent support and close friend support were also associated with self-worth longitudinally. Preliminary ANOVAs were conducted to assess whether there were significant differences in self-worth at pretest based on gender or grade, and there were no differences. We also used $t$-tests to compare students who completed both timepoints to those who completed only the pre-test, and there were no significant differences in perceptions of neighborhood disadvantage, global self-worth, and social support from any source (parent, teacher, friend, classmate) between the two samples.

\section{Who Provides Various Types of Support?}

Frequencies were used to investigate whom students listed as providing the three different types of social support (emotional, tangible, and informational; see Table 2). The sources named most often were similar, regardless of which function of support was queried. Mothers were overwhelmingly named as providing all three types of support (49-60\%). In comparison, fathers were listed as sources of these types of support $22-24 \%$ of the time. Friends were also cited as a major source of support, particularly for emotional and tangible support (29-31\%) compared to $24 \%$ for informational support. Grandmothers were named frequently (22-29\%), particularly for emotional support, and sisters were consistently supportive for all three types of needs $(27 \%)$. Teachers were listed frequently (26\%) for informational support, compared to their ratings for other types of support (6-8\%). In terms of 
Table 2 Types of social support from various sources

\begin{tabular}{lcll}
\hline Source of support & \multicolumn{3}{l}{ Type of support } \\
\cline { 2 - 4 } & $\begin{array}{l}\text { Emotional } \\
\%(\mathrm{n})\end{array}$ & $\begin{array}{l}\text { Tangible } \\
\%(\mathrm{n})\end{array}$ & $\begin{array}{l}\text { Informational } \\
\%(\mathrm{n})\end{array}$ \\
\hline Mother & $60.0 \%(78)$ & $48.5 \%(63)$ & $54.6 \%(71)$ \\
Father & $23.8 \%(31)$ & $23.8 \%(31)$ & $21.5 \%(28)$ \\
Grandmother & $28.5 \%(37)$ & $24.6 \%(32)$ & $22.3 \%(29)$ \\
Grandfather & $2.3 \%(3)$ & $6.2 \%(8)$ & $5.4 \%(7)$ \\
Sister/stepsister & $26.2 \%(34)$ & $26.9 \%(35)$ & $26.9 \%(35)$ \\
Brother/stepbrother & $15.4 \%(20)$ & $20.0 \%(26)$ & $16.2 \%(21)$ \\
Mom's boyfriend/ & $1.5 \%(2)$ & $5.4 \%(7)$ & $4.6 \%(6)$ \\
stepfather & & & \\
Friend & $31.5 \%(41)$ & $29.20 \%(38)$ & $23.8 \%(31)$ \\
Aunt & $14.6 \%(19)$ & $20.0 \%(26)$ & $16.9 \%(22)$ \\
Uncle & $12.3 \%(16)$ & $13.1 \%(17)$ & $6.2 \%(8)$ \\
Teacher & $8.5 \%(11)$ & $6.2 \%(8)$ & $26.2 \%(34)$ \\
Boy/girlfriend & $1.5 \%(2)$ & $2.3 \%(3)$ & $0.8 \%(1)$ \\
Cousin & $17.7 \%(23)$ & $12.3 \%(16)$ & $15.4 \%(20)$ \\
Other & $17.0 \%(22)$ & $15.4 \%(20)$ & $16.2 \%(21)$ \\
\hline
\end{tabular}

"other" many students named other female relatives, mostly godmothers and great-grandmothers as providing all three types of support.

\section{Main Effects vs. Stress-Buffering Models of Social Support}

Hierarchical multiple regressions were used to test the main-effects and stress-buffering models of social support (parent, teacher, classmate, and close friend) on global selfworth, in the context of neighborhood disadvantage. Subscales from the Social Support for Children Scale and the Neighborhood Disadvantage Scale were centered prior to creating multiplicative terms per Aiken et al. (1991). For cross-sectional analyses, there were two steps: first neighborhood disadvantage and all four social support subscales (parent, teacher, classmate, close friend) were entered (main effect), and second, the interaction between support and neighborhood disadvantage was entered (buffering effect). For the longitudinal analyses, first, initial selfworth was entered; second, neighborhood disadvantage and all four social support subscales were entered (main effect). Third, the interaction between each source of support and neighborhood disadvantage was entered (buffering effect). By including all of the support subscales in the same model, we are able to examine the unique influence of each source of support, taking into account all of the other sources of support.

The findings were consistent with a main-effects model of support for close friend support (cross-sectionally) and parent support (longitudinally), suggesting that more
Table 3 Main-effects model results: neighborhood disadvantage and social support predicting global self-worth

\begin{tabular}{lrllllll}
\hline Predictor variable & $\mathrm{B}$ & $\mathrm{SEB}$ & Beta & $\mathrm{t}$ & $\mathrm{R}^{2}$ & $\mathrm{~F}$ \\
\hline (Cross-sectional: predicting global self-worth at time 1) & .22 & $7.15^{* *}$ \\
Neighborhood & -.44 & .21 & -.17 & $-2.10^{*}$ & & \\
disadvantage & & & & & & \\
Parent support & .18 & .10 & .18 & 1.89 & & \\
Teacher support & .04 & .10 & .03 & .39 & & \\
Classmate support & .11 & .10 & .10 & 1.04 & & \\
Close friend support & .28 & .09 & .28 & $3.30^{* *}$ & & \\
(Longitudinal: predicting global self-worth and time 2) & & \\
Step 1 & & & & & .32 & $39.47^{* *}$ \\
$\quad$ Global self-worth T1 & .56 & .09 & .57 & $6.28^{* *}$ & & \\
Step 2 & & & & & .38 & $7.84^{* *}$ \\
Global self-worth T1 & .48 & .11 & .48 & $4.50^{* *}$ & & \\
Neighborhood & -.11 & .24 & -.04 & -.46 & & \\
disadvantage & & & & & & \\
Parent support & .29 & .12 & .26 & $2.39^{*}$ & & \\
Teacher support & -.04 & .12 & -.03 & -.35 & & \\
Classmate support & -.08 & .12 & -.08 & -.67 & & \\
Close friend support & .08 & .11 & .08 & .71 & & \\
\hline
\end{tabular}

$* * p<.01 ; * p<.05$

support from close friends and parents was beneficial for everyone in terms of its association with higher self-worth, rather than differentially effective depending on levels of perceived neighborhood disadvantage (See Table 3). Teacher and classmate support were not significantly associated with global self-worth in either model. There was no evidence for the stress-buffering models in either the crosssectional or longitudinal results, as none of the interactions were significant.

\section{Discussion}

We examined the social networks of urban, at-risk African American adolescents to determine who provided different types of support. We also tested two theoretical models of support, the main-effects model and the stress-buffering model to examine support from different sources in the context of chronic neighborhood stressors in relation to global self-worth.

\section{Social Support Networks}

We found African American youth identified many different people as providing support. Youth consistently listed the female members of their families-mothers, grandmothers, sisters, and aunts-as support providers. For each of the three types of support (emotional, tangible, and 
informational), they most often named their mothers as providing the support followed by their friends for emotional and instrumental support. Teachers were most likely listed as sources of informational support, versus emotional or instrumental support. Participants frequently named other female supports, mostly great grandmothers and godmothers, as providing all three types of support. Male family members that were listed included fathers, brothers, grandfathers, and mother's boyfriend/stepfathers, with fathers being listed most often. These findings are significant, given the dearth of research that has explored the social networks of African American at-risk youth, as more published work has focused on adults.

The tremendous support provided by women in this study underscores the pivotal role of women in African American families (Boyd-Franklin and García-Preto 1994). Women have traditionally played the role of caretaker in this community, not only for their own children, but for others' children as well (Greene 1994). Kinship networks include both extended biological and non-biological family members, and these family members share in family responsibility, thereby providing alternative role models, sources of support, and respite for mothers (Greene 1994). Common listings of extended family members is consistent with research demonstrating that even at young ages, African American children were likely to include extended family as central support figures and rely heavily on them (Bost et al. 2004).

The lower levels of support by men should not underestimate the importance of fathers and male relatives in the African American community, as paternal support has been associated with less depression (Bean et al. 2006). However, some children may be without this support. This may be caused by the oppression that men face in this community, leading to difficulties in obtaining gainful employment and overrepresentation in jails. Some have theorized that when men are not able to provide monetarily for their children, they are more likely to withdraw from family life (e.g., Gavin et al. 2002). In this way, economic oppression of men may increase the role of women in these families.

In many cases, students named the same people at similar frequencies for emotional, tangible, and informational support, and these similarities across support function are consistent with research indicating stability in support network structures among African American preschool students (Bost et al. 2004). There were also some interesting patterns of differences in functional support that emerged. Mothers were named most frequently as providers of emotional support, then informational support, and tangible support least frequently, while brothers, aunts, and uncles were noted as providing more tangible support compared to other types of support they provided.
Although mothers were still the primary providers of tangible support, given the economic challenges represented within this sample, it makes sense that youth may need to look to others to ask for additional things they need or want.

Regarding informational support, teachers were listed as informational support providers $(26 \%)$ much more frequently than providing other types of support (6-8\%). Of course, this may in many cases apply to coursework, but it is also likely that teachers serve as role models (Bru et al. 2001) and help students with other types of problems and decisions. Teacher support and acceptance have been associated with better academic (e.g., Elias and Haynes 2008) and behavioral outcomes (e.g., Benhorin and McMahon 2008). Students reported receiving less informational support from friends, grandmothers, and uncles compared to other types of support they received from these individuals.

\section{Main Effect vs. Stress-Buffering Models of Social Support}

We examined the main-effects versus stress-buffering models of social support in relation to global self worth in the context of neighborhood disadvantage. Our results support the main effect model of social support. Crosssectionally, support from close friends was related to global self-worth. Parent support was the only source of social support found to have a significant longitudinal effect on self-worth. Students did perceive the highest levels of support as coming from their parents, and this is consistent with the network findings described above, in which mothers were listed most frequently as giving emotional, tangible, and instrumental support. Increased parental support has been associated with increased self-esteem (Greene and Way 2005) and adolescent global self-worth (Laursen et al. 2006).

Whereas parental support is often associated with positive outcomes in youth, findings on peer support have been less consistent, with some showing positive effects and others reporting negative effects (Zimmerman et al. 2000). This mixture in findings may be due in part to the fact that the effects of peer support depend on the values of the peer group (Cauce et al. 1996). In our study, friends were identified as providing all three forms of social support; however, there was not a longitudinal relationship between friend support and self-worth. These findings suggest that at any moment in time, support from friends is associated with a child's current sense of self-worth, but over time, parental support is more influential in shaping and maintaining an adolescent's sense of self-worth and mental health (e.g., Dubow et al. 1997; Zimmerman et al. 2000). This may be due to the relatively transitory nature of some 
friendships (Chan and Poulin 2007) compared to family relationships. It is also possible that close friends provide youth with certain types of competence over time, but not global self-worth. Indeed, Laursen and colleagues (2006) found that social support from a close friend is longitudinally related to certain types of interpersonal competence, such as social acceptance, friendship competence, and romantic competence.

Although previous research has shown that a close relationship with a teacher is positively correlated with the social, emotional, and academic adjustment of the child (Murray and Greenberg 2000), we did not find a relation between teacher support and global self-worth in the current study. Perhaps this is due in part to the fact that in this study, although teachers provided informational support to students, they did not provide very much emotional or tangible support. Further, children who attend inner-city public schools may not receive sufficient individual time and attention from their teachers unless their behavior is disruptive (Vondra 1999).

The results of this study do not support the stress-buffering hypothesis of social support, as it did not buffer the effects of neighborhood disadvantage on a youth's sense of self-worth. Our findings are consistent with some recent studies of African American youth (e.g., Paxton et al. 2004; Salazar et al. 2004), but the extant research is equivocal in its support of the stress-buffering hypothesis for social support. One reason may be specificity in terms of the relations among particular types of stressors, moderating factors, and youth outcomes (McMahon et al. 2003). Indeed, stress-buffering has been found to depend on the outcome of interest (Rosenfeld et al. 2006), and there are not enough theory-driven studies that test full models of specificity to make adequate comparisons across studies. Further, environment-based moderators, such as social support, have been characterized by variability in conceptualization and measurement, limiting conclusions that can be drawn (Grant et al. 2006). Thus, there is a need for further research in conceptualization and measurement of these constructs, as well as theory-driven, longitudinal studies with at-risk populations to better understand the roles of various types and sources of support in promoting positive outcomes and reducing risk.

There are several strengths and limitations represented in this study. In terms of strengths, our study was theorydriven, and we assessed positive influences and outcomes among an often pathologized, at-risk, understudied population. We also used multiple measures of support, assessing both structural and functional support, in terms of who provides support and how it influences youth. In terms of limitations, this study relied on self-report measures, was relatively short in duration, and included only one measure of stressors and one outcome. Further, the measures did not tap into support that was specifically provided to cope with the stressor of neighborhood disadvantage. Obtaining multiple perspectives and comparing models that assess several stressors and several outcomes could improve the specificity of our findings. Our measure of functional support was also limited in that it did not measure the adequacy of the support received from each person.

There is a need to further examine the complicated relations among different types and sources of social support, stressors, and psychosocial outcomes with diverse samples. It appears that parent support plays an especially important role in promoting global self-worth, so providing services to parents, as well as children may be beneficial. Finally, studying potential protective factors for youth who experience chronic stressors should not diminish our efforts to reduce these larger systemic issues related to poverty, racism, violence, gangs and drugs that must be addressed.

Open Access This article is distributed under the terms of the Creative Commons Attribution Noncommercial License which permits any noncommercial use, distribution, and reproduction in any medium, provided the original author(s) and source are credited.

\section{References}

Aiken, L. S., West, S. G., \& Reno, R. R. (1991). Multiple regression: testing and interpreting interactions. Newbury Park, CA: Sage.

Bean, R. A., Barber, B. K., \& Crane, D. R. (2006). Parental support, behavioral control, and psychological control among African American youth: The relationship to academic grades, delinquency, and depression. Journal of Family Issues, 27, 1335-1355.

Belle, D. (1984). Inequality and mental health: Low-income and minority women. In L. Walker (Ed.), Women and mental health policy (pp. 135-150). Beverly Hills, CA: Sage.

Benhorin, S., \& McMahon, S. D. (2008). Exposure to violence and aggression: Protective roles of social support among urban African American youth. Journal of Community Psychology., 36(6), 723-743.

Bost, K. K., Vaughn, B. E., Boston, A. L., Kazura, K. L., \& O’Neal, C. (2004). Social support networks of African-American children attending head start: A longitudinal investigation of structural and supportive network characteristics. Social Development, 13, 393-412.

Boyd-Franklin, N., \& García-Preto, N. (1994). Family therapy: The cases of African American and Hispanic women. In L. ComasDíaz \& B. Greene (Eds.), Women of color: Integrating ethnic and gender identities in psychotheraphy (pp. 239-264). New York: Guilford.

Brown, D. (2008). African American resiliency: Examining racial socialization and social support as protective factors. Journal of Black Psychology, 34, 32-48.

Bru, E., Murberg, T. A., \& Stephens, P. (2001). Social support, negative life events and pupil misbehaviour among youth Norweigian adolescents. Journal of Adolescence, 24, 715-727.

Cauce, A. M., Mason, C., Gonzales, N., Hiraga, Y., \& Lui, G. (1996). Social support during adolescence: Methodological and theoretical considerations. In K. Hurrelmann \& S. F. Hamilton (Eds.), Social problems and social contexts in adolescence (pp. 131-151). New York: Aldine de Gruyter. 
Chan, A., \& Poulin, F. (2007). Monthly changes in the composition of friendship networks in early adolescence. Merrill-Palmer Quarterly: Journal of Developmental Psychology, 53(4), 578-602. doi:10.1353/mpq.2008.0000.

Chicago Public Schools. (1999). Department of Research and Evaluation School Information Database. Retrieved February 2, 2002 from http://acct.multi1.cps.k12.il.us/.

Cohen, S., \& Wills, T. A. (1985). Stress, social support, and the buffering hypothesis. Psychological Bulletin, 98(2), 310-357.

Dubow, E. F., \& Ullman, D. G. (1989). Assessing social support in elementary school children: The children's social support. Journal of Clinical Child Psychology, 18, 52-64.

Dubow, E. F., Edwards, S., \& Ippolito, M. F. (1997). Life stressors, neighborhood disadvantage, and resources: A focus on inner-city children's adjustment. Journal of Clinical Child Psychology, 26, 130-144.

Elias, M. J., \& Haynes, N. M. (2008). Social competence, social support, and academic achievement, in minority, low-income, urban elementary school children. School Psychology Quarterly, 23, 474-495.

Gavin, L., Black, M. M., Minor, S., Abel, Y., Papas, M. A., \& Bentley, M. E. (2002). Young, disadvantaged fathers' involvement with their infants: An ecological perspective. Journal of Adolescent Health, 31, 266-276.

Gaylord-Harden, N. K., Ragsdale, B. L., Mandara, J., Richards, M., \& Petersen, A. C. (2007). Perceived support and internalizing symptoms in African American adolescents: Self-esteem and ethnic identity as mediators. Journal of Youth and Adolescence, 36, 77-88.

Grant, K. E., Compas, B. E., Thurm, A. E., McMahon, S. D., Gipson, P. Y. J., Krochoch, K., et al. (2006). Stressors and child adolescent psychopathology: Evidence of moderating and mediating effects. Clinical Psychology Review, 26, 257-283.

Greene, B. (1994). African American women. In L. Comas-Diaz \& B. Greene (Eds.), Women of color (pp. 10-29). Guilford: New York.

Greene, M., \& Way, N. (2005). Self-esteem trajectories among ethnic minority adolescents: A growth curve analysis of the patterns and predictors of change. Journal of Research on Adolescence, $15,151-178$

Harter, S. (1985a). Manual for the social support scale for children. Denver: University of Denver.

Harter, S. (1985b). Manual for the self perception profile for children. Denver: University of Denver.

Harter, S., Waters, P., \& Whitesell, N. R. (1998). Relational selfworth: Differences in perceived worth as a person across interpersonal contexts among adolescents. Child Development, 69(3), 756-766.

Henrich, C. C., \& Shahar, G. (2008). Social support buffers the effects of terrorism on adolescent depression: Findings from Sderot, Israel. Journal of the American Academy of Child \& Adolescent Psychiatry, 47, 1073-1076.

Hill, H. M., Levermore, M., Twaite, J., \& Jones, L. P. (1996). Exposure to community violence and social support as predictors of anxiety and social emotional behavior among African American children. Journal of Child and Family Studies, 5, 399-414.

Hirsch, B. J., Mickus, M., \& Boerger, R. (2002). Ties to influential adults among Black and White adolescents: Culture, social class, and family networks. American Journal of Community Psychology, 30, 289-303.

Holt, M. K., \& Espelage, D. L. (2005). Social support as a moderator between dating violence victimization and depression/anxiety among African American and Caucasian adolescents. School Psychology Review, 34, 309-328.

Kerpelman, J. L., Eryigit, S., \& Stephens, C. J. (2008). African American adolescents' future education orientation: Associations with selfefficacy, ethnic identity, and perceived parental support. Journal of Youth and Adolescence, 37, 997-1008.
Laursen, B., Furman, W., \& Mooney, K. S. (2006). Predicting interpersonal competence and self-worth from adolescent relationships and relationship networks: Variable-centered and person-centered perspectives. Merrill-Palmer Quarterly, 52, $572-600$

Luthar, S. S. (1991). Vulnerability and resilience: A study of high-risk adolescents. Child Development, 62, 600-616.

Marin, T. J., Martin, T. M., Blackwell, E., Stetler, C., \& Miller, G. E. (2007). Differentiating the impact of episodic and chronic stressors on hypothalamic-pituitary-adrenocortical axis and regulation in young women. Health Psychology, 26, 447-455.

McMahon, S. D., Grant, K. E., Compas, B. E., \& Thurm, A. E. (2003). Stress and psychopathology in children and adolescents: Is there evidence of specificity? Journal of Child Psychology and Psychiatry, 44(1), 107-133.

Murray, C., \& Greenberg, M. T. (2000). Children's relationship with teachers and bonds with school: An investigation of patterns and correlates in middle childhood. Journal of School Psychology, 38(5), 423-445.

Overstreet, S., Dempsey, M., Graham, D., \& Moely, B. (1999). Availability of family support as a moderator of exposure to community violence. Journal of Clinical Child Psychology, 28, $151-159$.

Owens, T. J. (1994). Two dimensions of self-esteem: Reciprocal effects of positive self-worth and self-deprecation on adolescent problems. American Sociological Review, 59, 391-407.

Paxton, K. C., Robinson, W. L., Shah, S., \& Schoeny, M. E. (2004). Psychological distress for African-American adolescent males: Exposure to community violence and social support as factors. Child Psychiatry and Human Development, 34, 281-295.

Pina, A. A., Villalta, I. K., Ortiz, C. D., Gottschall, A. C., Costa, N. M., \& Weems, C. F. (2008). Social support, discrimination, and coping as predictors of posttraumatic stress reactions in youth survivors of Hurricane Katrina. Journal of Clinical Child \& Adolescent Psychology, 37, 564-574.

Robinson, N. S. (1995). Evaluating the nature of perceived support and its relation to perceived self-worth in adolescents. Journal of Research on Adolescence, 5(2), 253-280.

Rosenberg, M. (1986). Self-concept from middle childhood through adolescence. In J. Suls \& A. G. Greenwald (Eds.), Review: psychological perspective on the self. Hillsdale, NJ: Erlbaum.

Rosenfeld, L. B., Richman, J. M., Bowen, G. L., \& Wynns, S. L. (2006). In the face of a dangerous community: The effects of social support and neighborhood danger on high school students' school outcomes. Southern Communication Journal, $71,273-289$.

Salazar, L. F., Wingood, G. M., DiClemente, R. J., Lang, D. L., \& Harrington, K. (2004). The role of social support in the psychological well-being of African American girls who experience dating violence victimization. Violence and Victims, 19, $171-187$

Scarpa, A., \& Haden, S. C. (2006). Community violence victimization and aggressive behavior: The moderating effects of coping and social support. Aggressive Behavior, 32, 502-515.

Vondra, J. I. (1999). Commentary for "schooling and high-risk populations: The Chicago longitudinal study". Journal of School Psychology, 37(4), 471-479.

White, K. S., Bruce, S. E., Farrell, A. D., \& Kliewer, W. (1998). Impact of exposure to community violence on anxiety: A longitudinal study of family social support as a protective factor for urban children. Journal of Child and Family Studies, 7(2), 187-203.

Zimmerman, M. A., Ramirez-Valles, J., Zapert, K. M., \& Maton, K. I. (2000). A longitudinal study of stress-buffering effects for urban African-American male adolescent problem behaviors and mental health. Journal of Community Psychology, 28(1), 17-33. 